\title{
The mystery of persistent pulmonary hypertension: an idiopathic infantile arterial calcification
}

\author{
Huma Shaireen 1,2,3 , Alexandra Howlett ${ }^{1,3,4}$, Harish Amin ${ }^{1,2,3}$, Kamran Yusuf 1,2,3, Majeeda Kamaluddeen 1,2,3
} and Abhay Lodha ${ }^{1,2,3^{*}}$

\begin{abstract}
Background: Idiopathic infantile arterial calcification (IIAC) is a rare autosomal recessive disorder, characterized by wide spread calcifications in arterial walls, leading to vaso-occlusive ischaemia of multiple organs. Mortality is high, and there is no definitive treatment.

Case presentation: A male neonate, $36^{+5}$ weeks gestation, $2.81 \mathrm{~kg}$, was admitted to NICU for respiratory distress. At one hour of age, he was noted to be pale, hypoperfused, with weak pulses, a hyperdynamic precordium and a grade IVNI pansystolic murmur. The rest of his examination was normal. A chest X-ray showed massive cardiomegaly and pulmonary oedema. An echocardiogram (ECHO) indicated moderate persistent pulmonary hypertension (PPHN) of unclear etiology. A diagnosis of Idiopathic infantile arterial calcification was made and a trial of Editronate therapy was given without success.

Conclusion: IIAC is a rare disorder, it should be considered whenever a neonate presents with unexplainable cardiac failure, PPHN, echogenic vessels on X-ray/ultrasound and, or concentric hypertrophic ventricles on ECHO. Serial antenatal ultrasound findings of echogenic cardiac foci should raise the suspicion of IIAC. Further studies to determine the long term effects of Editronate on vascular calcifications, disease outcome, and other treatment options are needed.
\end{abstract}

Keywords: Neonate, Infantile arterial calcification, Pulmonary hypertension, Biphosphonate

\section{Background}

Idiopathic infantile arterial calcification (IIAC) is a rare autosomal recessive disorder associated with widespread calcification and degeneration of the elastic lamina of arteries [1]. Clinical manifestations are related to vasoocclusive disease of multiple organs [2].The association of IIAC with persistent pulmonary hypertension (PPHN) is rare $[3,4]$. We describe a newborn with IIAC who presented with PPHN and cardiac failure.

\section{Case presentation}

A male neonate, $36^{+5}$ weeks gestation, $2.81 \mathrm{~kg}$, was admitted at birth to neonatal intensive care unit (NICU)

\footnotetext{
* Correspondence: aklodha@ucalgary.ca

'Section of Neonatology, Department of Pediatrics, University of Calgary, Calgary, Alberta, Canada

${ }^{2}$ Foothills Medical Centre, Calgary, Alberta, Canada

Full list of author information is available at the end of the article
}

for respiratory distress. The family history was notable for parental consanguinity. He was delivered to a G2 P1 mother after an uncomplicated pregnancy by emergency caesarean section for fetal heart rate abnormalities. Apgar scores were $9^{1}$ and $9^{5}$, with no resuscitation required. At one hour of age, he was noted to be pale, hypoperfused, with weak pulses, a hyperdynamic precordium and a grade IV/VI pansystolic murmur. The rest of his examination was normal. A chest $\mathrm{x}$-ray showed massive cardiomegaly and pulmonary oedema. An echocardiogram (ECHO) indicated moderate PPHN. He required intubation, and treatment with inhaled nitric oxide (iNO), sildenafil, furosemide and milrinone.

Complete blood counts, electrolytes, blood cultures, enterovirus panel, metabolic investigations and cardiac enzymes were normal. Molecular genetic testing for Myoclonic epilepsy with ragged red fibers (MERRF),

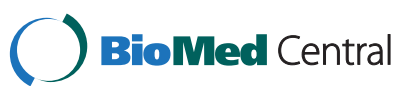


Mitochondrial encephalomyopathy, lactic acidosis, and stroke-like episodes (MELAS) and Neuropathy, Ataxia, and Retinitis Pigmentosa (NARP) syndrome was negative. Repeated ECHO examinations showed normal systemic and pulmonary venous drainage, thickened semilunar and tricuspid valve leaflets, and concentric left ventricular hypertrophy. An ECG was negative for ischaemic changes. Computed chest angiography showed incidental mild narrowing of the left pulmonary vein, which was not noticed in any of the ECHO examinations.

A detailed review of an abdominal X-ray (Figure 1), and computed tomography (CT) scan found calcified vessels, suggested the clinical diagnosis of IIAC on day 20 of life. An ECHO on day 20 of life also identified an echogenic aorta, echogenic coronary arteries with normal pulmonary veins. Echodensities were also noticed in the main and branch pulmonary arteries. Calcifications of the abdominal aorta (Figure 2), renal artery and intracranial thalamic vessels were also evident on ultrasound. No mutation of ectonucleotide pyrophosphatase/ phosphodiesterase 1 (ENPP1) gene was identified. Blood was stored for DNA banking to identify mutations in other genetic sequences.

The baby was extubated on day 20, iNO and milirinone were discontinued gradually. The Sildenafil was tapered to $1 \mathrm{mg} / \mathrm{kg} /$ day. The infant's subsequent course in NICU was complicated by recurrent abdominal distension, feeding intolerance, irritability, pyrexia and systemic hypertension.

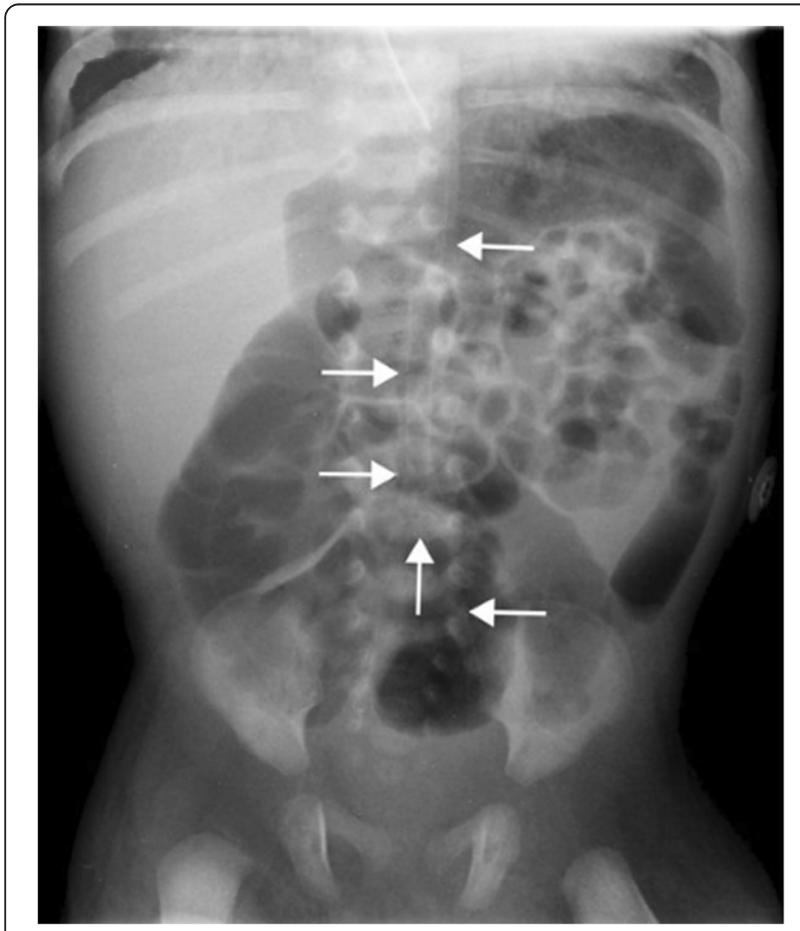

Figure 1 Abdominal X-ray showing calcified descending aorta.

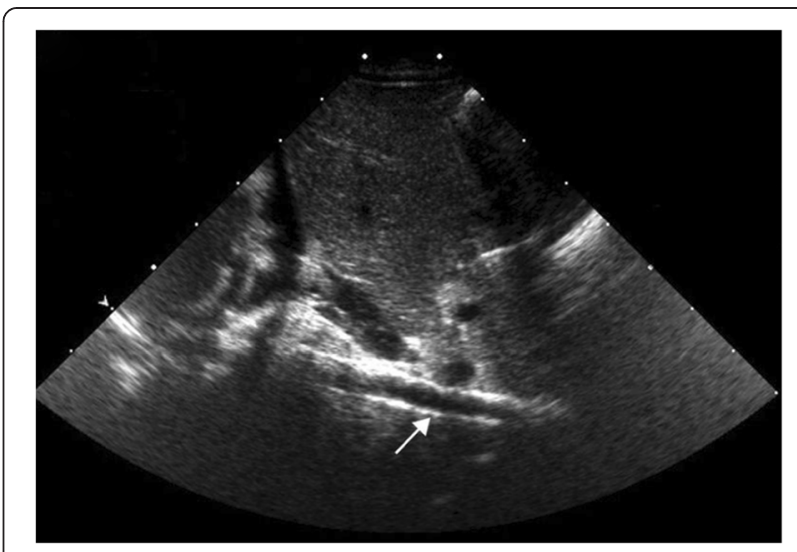

Figure 2 Ultrasound of abdomen showing calcified aorta.

Oral Editronate Sodium (10 mg/kg/day, twice a day) was started on day 40 . He was discharged home at 75 days of age on Editronate $20 \mathrm{mg} / \mathrm{kg} /$ day; Sildenafil $1.5 \mathrm{mg} / \mathrm{kg} /$ day; and Captopril $1.2 \mathrm{mg} / \mathrm{kg} /$ day. He developed fever and respiratory distress one day after discharge, requiring readmission. The respiratory viral panel, and sepsis work up were normal but troponin was elevated $(0.53 \mathrm{ug} / \mathrm{L}$, normal value $0.0-0.1 \mathrm{ug} / \mathrm{L}$ ). Twelve leads ECG was not available but a tracing showed S-T segment elevation in lead II. Resuscitation code was revised. Palliative care was initiated with parental consent, and no escalation of pulmonary hypertension therapy was advised. Despite ventilatory and inotropic support for hypotension, he died at three months of age. The parents declined consent for autopsy, skin/ arterial biopsy and sibling genetic screening.

\section{Discussion}

IIAC was first described in 1901 [1]. It is clinically and genetically a heterogeneous disease $[2,5,6]$. The most described pathogenesis in $80 \%$ of cases is a mutation and inactivation of ectonucleotide pyrophosphatase/phosphodiesterase 1 (ENPP1) gene [7-11]. ENPP1 is expressed on fibroblasts, osteoblasts and hepatocytes [7]. ENPP1 gene has nucleotide pyrophosphohydrolase activity and produces inorganic pyrophosphate (PPi) [11]. PPi prevents deposition of calcium hydroxyapatite crystal in the arteries. The mutation of ENPP1 gene results in variable degrees of calcification and intimal fibrosis of medium and large arteries of cardiac and renal vascular system [9]. There are other known (ABCC6, NT5E and SLC 20A2) and unknown gene mutations, associated with arterial calcification $[5,12,13]$.

A literature review stated that almost $48 \%$ of patients presented at birth or in-utero, while $52 \%$ cases were identified during infancy [1]. Fetal complications include: cardiac arrhythmias, heart failure, hydrops fetalis and fetal demise, often early in pregnancy $[2,14,15]$. During the neonatal period, $30-40 \%$ of infants presented with respiratory or cardiac failure [1]. Seizures, renal failure, 
hypertension, arrhythmias and gut obstruction/infarction were seen in $1 \%$ to $8 \%$ of neonates [1]. In infants, common manifestations include: irritability, feeding difficulties and poor growth [1]. Coronary artery calcification was the worst prognostic indicator and majority of infants expired due to myocardial infarction $[1,16]$.

IIAC is a diagnosis of exclusion [2]. Absence of other infantile arterial calcification disorders, normal serum calcium/phosphrous panel and a positive family history suggest IIAC [1]. The gold standard for diagnosis is arterial biopsy $[1,8,10,17]$. Evidence of calcified arterial walls on X-rays of the chest/abdomen and long bones, $\mathrm{CT}$ of chest, $\mathrm{ECHO}$, cranial and abdominal ultrasound are other helpful diagnostic findings $[2,8]$.

Antenatal screening can be done by DNA analysis for ENPP1 mutation and by serial ultrasounds [15]. Detection of echogenic intracardiac foci, arterial calcification, dilated or hypertrophied cardiac chambers, hydrops fetalis are strong indicators of IIAC [14]. Families can be screened for calcified arteries by performing ultrasounds, X-rays and echocardiography [15].

In the literature only few cases of IIAC with PPHN have been reported $[4,10]$. One patient received Editronate $15 \mathrm{mg} / \mathrm{kg} /$ day, but had remained hypertensive, ventilator dependant and died at 35 days of life [10]. Extensive calcification of major vessels was confirmed on autopsy. Our patient also had PPHN with other systemic signs attributable to IIAC.

Reports in the literature suggest resolution of arterial calcification with Editronate (Biphosphonate sodium) treatment $[8,18]$. The longest survival has been reported in a 25-year-old man who was treated with Editronate (Biphosphonate sodium) [1]. However, all patients who received Editronate had mild or no evidence of coronary involvement. Editronate is an analogue of PPi [8]. It alters the calcium balance by interfering with hydroxyapatite crystal formation and inhibits the calcium deposition in the existing calcified lesions. The recommended dose and duration of this treatment varies in the literature $[8,18]$. Our patient was maximized to $20 \mathrm{mg} / \mathrm{kg} /$ day, twice a day. Serial calcium, phosphate, alkaline phosphatase and wrist $\mathrm{X}$-rays were done to monitor the side effects of the drug $[18,19]$. Vitamin D was also given to prevent Editronate induced vitamin $\mathrm{D}$ deficiency. No resolution of calcification was seen in the serial radio-imaging studies.

Our patient also had coronary artery calcification, a common cause of sudden ischemic heart failure [1]. We assumed that myocardial ischemia was the probable cause of death because of high troponin levels. Arterial biopsy and autopsy were not performed as per parent's wishes.

\section{Conclusions}

Though IIAC is a rare disorder, it should be considered whenever a neonate presents with unexplainable cardiac failure, PPHN, echogenic vessels on X-ray/ ultrasound and, or concentric hypertrophic ventricles on ECHO. Serial antenatal ultrasound findings of echogenic cardiac foci should raise the suspicion of IIAC. Every effort should be made to establish the diagnosis by arterial and skin fibroblast biopsy. Further studies to determine the long term effects of Editronate on vascular calcifications, disease outcome, and other treatment options are needed.

\section{Consent}

Written informed consent was obtained from the patient for publication of this case report and any accompanying images. A copy of the written consent is available for review by the Editor of this journal.

\section{Abbreviations}

ENPP1: ectonucleotide pyrophosphatase/phosphodiesterase 1; ABCC6: ATP-binding cassette (ABC) transporters; NT5E: 5'-nucleotidase, ecto (CD73) and; SLC 20A2: SLsolute carrier family 20 (phosphate transporter), member 2.

\section{Competing interest}

There are no competing interests in the report.

\section{Authors' contributions}

HS Has written the first and revised draft of the manuscript, provided patient care in the NICU and approved the final manuscript as submitted. AH Reviewed and edited the manuscript, and approved the final revised manuscript as submitted. HA Critically reviewed the manuscript and approved the final revised manuscript as submitted. KY Provided patient care, helped in the literature search, reviewed the manuscript and approved the final revised manuscript as submitted. MK Reviewed the manuscript and approved the final revised manuscript as submitted. AL Provided patient care, obtained consent for publication and formatted bibliography, Reviewed and revised the first draft and approved the final revised manuscript as submitted.

\section{Authors' information}

HS. MD, Clinical Fellow (4 ${ }^{\text {th }}$ year), University of Calgary, Calgary, Canada AH. MD, FRCPC, FAAP, Clinical Associate Professor, Department of Pediatrics, University of Calgary, Chief of Neonatology, Alberta Children's Hospital, Calgary HA. MD, FRCPC, FAAP, Associate Professor, Department of Pediatrics, University of Calgary, Chief of Neonatology, South East Hospital, Calgary. KY. MBBS, FAAP, Assistant Professor, Department of Pediatrics, University of Calgary MK. MBBS, MD, MRCPI, FAAP, Director, Neonatal- Perinatal Medicine Fellowship Program, University of Calgary.

AL. MBBS, MD, DM, MSC, Chairman CME, Epidemiologist, CME, Assistant Professor, Department of Pediatrics and Community Health Sciences, University of Calgary.

\section{Acknowledgements}

We thank the parents of our patient for their cooperation and support, and for providing consent for publication. We also thank hospital nurses for their assistance with the management of this patient.

\section{Author details}

${ }^{1}$ Section of Neonatology, Department of Pediatrics, University of Calgary, Calgary, Alberta, Canada. ${ }^{2}$ Foothills Medical Centre, Calgary, Alberta, Canada. ${ }^{3}$ Alberta Health Services, Calgary, Alberta, Canada. ${ }^{4}$ Alberta Children's

Hospital, Calgary, Alberta, Canada.

Received: 29 December 2012 Accepted: 11 July 2013

Published: 16 July 2013

\section{References}

1. Chong CR, Hutchins GM: Idiopathic infantile arterial calcification: the spectrum of clinical presentations. Pediatr Dev Pathol 2008, 11(5):405-415.

2. van der Sluis IM, Boot AM, Vernooij M, Meradji M, Kroon AA: Idiopathic infantile arterial calcification: clinical presentation, therapy and longterm follow-up. Eur J Pediatr 2006, 165(9):590-593. 
3. Farquhar J, Makhseed N, Sargent M, Taylor G, Osiovich H: Idiopathic infantile arterial calcification and persistent pulmonary hypertension. Am J Perinatol 2005, 22(3):121-125.

4. Morton R: Idiopathic arterial calcification in infancy. Histopathology 1978, 2(6):423-432.

5. Nitschke Y, Baujat G, Botschen U, Wittkampf T, du Moulin M, Stella J, Le Merrer M, Guest G, Lambot K, Tazarourte-Pinturier MF, et al: Generalized arterial calcification of infancy and pseudoxanthoma elasticum can be caused by mutations in either ENPP1 or ABCC6. Am J Hum Genet 2012, 90(1):25-39.

6. Hofmann Bowman MA, McNally EM: Genetic pathways of vascular calcification. Trends Cardiovasc Med 2012, 22(4):93-98.

7. Rutsch F, Ruf N, Vaingankar S, Toliat MR, Suk A, Hohne W, Schauer G Lehmann M, Roscioli T, Schnabel D, et al: Mutations in ENPP1 are associated with 'idiopathic' infantile arterial calcification. Nat Genet 2003, 34(4):379-381.

8. Ramjan KA, Roscioli T, Rutsch F, Sillence D, Munns CF: Generalized arterial calcification of infancy: treatment with bisphosphonates. Nat Clin Pract Endocrinol Metab 2009, 5(3):167-172.

9. Kalal IG, Seetha D, Panda A, Nitschke Y, Rutsch F: Molecular diagnosis of generalized arterial calcification of infancy (GACl). J Cardiovasc Dis Res 2012, 3(2):150-154

10. Guimaraes S, Lopes JM, Oliveira JB, Santos A: Idiopathic infantile arterial calcification: a rare cause of sudden unexpected death in childhood. Patholog Res Int 2010, 2010:185314.

11. Rutsch F, Vaingankar S, Johnson K, Goldfine I, Maddux B, Schauerte P, Kalhoff H, Sano K, Boisvert WA, Superti-Furga A, et al: PC-1 nucleoside triphosphate pyrophosphohydrolase deficiency in idiopathic infantile arterial calcification. Am J Pathol 2001, 158(2):543-554.

12. Numakura C, Yamada M, Ariyasu D, Maesaka A, Kobayashi H, Nishimura G, Ikeda M, Hasegawa Y: Genetic and enzymatic analysis for two Japanese patients with idiopathic infantile arterial calcification. J Bone Miner Metab 2006, 24(1):48-52.

13. Nitschke Y, Rutsch F: Genetics in arterial calcification: lessons learned from rare diseases. Trends Cardiovasc Med 2012, 22(6):145-149.

14. Cansu A, Ahmetoglu A, Mutlu M, Guven S, Osmanagaoglu MA: Idiopathic infantile arterial calcification: prenatal diagnosis and postnatal presentation. Clin Exp Obstet Gynecol 2010, 37(1):73-75.

15. Nasrallah FK, Baho H, Sallout A, Qurashi M: Prenatal diagnosis of idiopathic infantile arterial calcification with hydrops fetalis. Ultrasound Obstet Gynecol 2009, 34(5):601-604.

16. Mehta S, Sterba RJ: Boyle GJ. Aziz PF: Unusual Cause of Myocardial Ischemia in an Infant. Congenit Heart Dis; 2012.

17. Heuser CC, Puchalski M, Kennedy A, Sangle N, Manuck T, Andres R: Radiographic and pathologic evaluation of idiopathic infantile arterial calcification. Obstet Gynecol 2010, 115(2 Pt 2):465-468.

18. Rutsch F, Boyer P, Nitschke Y, Ruf N, Lorenz-Depierieux B, Wittkampf T, Weissen-Plenz G, Fischer RJ, Mughal Z, Gregory JW, et al: Hypophosphatemia, hyperphosphaturia, and bisphosphonate treatment are associated with survival beyond infancy in generalized arterial calcification of infancy. Circ Cardiovasc Genet 2008, 1(2):133-140.

19. Edouard T, Chabot G, Miro J, Buhas DC, Nitschke Y, Lapierre C, Rutsch F, Alos N: Efficacy and safety of 2-year etidronate treatment in a child with generalized arterial calcification of infancy. Eur J Pediatr 2011, 170(12):1585-1590.

doi:10.1186/1471-2431-13-107

Cite this article as: Shaireen et al:: The mystery of persistent pulmonary hypertension: an idiopathic infantile arterial calcification. BMC Pediatrics 2013 13:107.

\section{Submit your next manuscript to BioMed Central and take full advantage of:}

- Convenient online submission

- Thorough peer review

- No space constraints or color figure charges

- Immediate publication on acceptance

- Inclusion in PubMed, CAS, Scopus and Google Scholar

- Research which is freely available for redistribution

Submit your manuscript at www.biomedcentral.com/submit
C Biomed Central 